\title{
Analysis of Japanese Intransitive Verb and Transitive Verb Expressions Based on Different Perspectives Zongjie Wang ${ }^{1, a}$ and Jinghui Wang ${ }^{2}$ \\ ${ }^{1}$ Zhejiang Yuexiu University of Foreign Languages, ShaoXing 312000, China \\ ${ }^{2}$ Harbin Normal University, Harbin 150025, China ajie052003@163.com
}

Keywords: Intransitive Verb, Transitive Verb, Human viewpoint, Object viewpoint

\begin{abstract}
In Japanese, except for some grammars being able to express "can", possible expression of a verb can refer some abilities or conditions with possibility. This kind of possible expression is relative to a subject's will and wish. Therefore, the verb in its possible expression is full of will. Intransitive verb in Japanese is filled with will and express its own possible expression. However, when facing Japanese intransitive and transitive paired verbs, we are always confused to use its possible expression of Japanese intransitive verb or its transitive verb. This paper analyzes the possible expressions of Japanese intransitive verb or its transitive verb from the viewpoint of persons and objects respectively.
\end{abstract}

\section{Introduction}

For native Chinese speaking students learning Japanese, transitive-intransitives in Japanese language are easy to understand yet difficult to grasp. The reason why it's easy to understand is because intransitive verbs and transitive verbs exist in both of Chinese and Japanese [1]. The reason why it's difficult to grasp is because there are great differences in the expression, the ideological and cultural practices etc. between Chinese and Japanese [2]. As to possible expression, the verb is intransitive or transitive uses "neng" to express in Chinese. However, there are great differences between intransitive-transitive verb pairs in Japanese. So, Chinese students who are studying Japanese are confused about possible expression of intransitive-transitive verb pairs [3]. This paper analyses the possible expression of intransitive verb and transitive verb in Japanese in order to help the Japanese learners to accurately grasp the possible expression of intransitive-transitive verb pairs in Japanese.

In Japanese, only the will verbs with "(ra) reru" or "kotogadekiru" followed after it to express their possible states. However, no-will verbs are mostly intransitive verbs, which can express possibility itself, usually without "(ra) reru" or "kotogadekiru" followed [4][5].

\section{Classification of Intransitive-Transitive Verbs in Japanese}

The classification of transitive-intransitive verbs is significant for further discussion of their tenses. In Japanese, transitive-intransitive verbs can be divided into three categories[6][7]:

\section{Transitive-Intransitive Verb Pairs}

Intransitive verbs and transitive verbs that have the same roots or stems and the corresponding relations-between them.

For example: aku-akeru, hajimaru-hajimeru, hairu-ireru, ugoku-ugokasu.

\section{Transitive-Intransitive Verb Non-Pairs}

Intransitive verbs and transitive verbs that do not have the same roots or the corresponding relations and exist independently.

For example: intransitive iru, aru, iku; transitive stukuru, yomu, hanasu. 


\section{Transitive-Intransitive Sharing the Same Form of One Verb}

The verbs that functions as intransitive verbs as well as the transitive verbs.

For example: tsubomigaahiraku-kokotooaku, kageokatachinitomonau-yuujinotomonau.

\section{Possible Expressions of Intransitive-Transitive Verbs in Japanese}

Possible state of a verb shows the ability or possibility of sentient someone or something. Morita Yoshiyuki classifies the possible states into "the ability to confer" and "difficult situation of full actual cash, allowable "two categories [8]. Expressive forms of possible states are related to subject's will and wish. The prerequisite of using possible verbs is that the possible verb is a will verb. No-will verbs cannot express the will or wish of the subject, so they do not have a possible expression . For example:

watashi no ha wa jyoubu dewanai kara kataimono ga taberaremasen (I couldn't eat hard things because my tooth is not good.).

hayashisan wa cyounen nihon ni seikatsu shita node,nihogo ga hanasemaseru ( Mr.li can speak Japanese because of living in Japan year by year.).

mou shinshistu no mongen ga sugita kara,soto he ha derarenai (The door has been closed so we can't go out.).

It can be seen that "tabetai", "hanashitai", "detail" are will verbs, expressing the ability or possibility of wish coming true, which is the prerequisite of using possible verbs. As transitive verbs are generally will verbs, therefore, they can be used in possible sentence. When transitive-intransitive verb pairs appear, there are two possible expressions, possible states of transitive verbs and possible expression of intransitive verbs themselves.

\section{From the Perspective of Person and Object to See the Difference in the Use of the Verb}

\section{The Differences of Intransitive-Transitive Verb Pairs in Possible Expression Aspect}

When we want to express that someone perform an action on something from persons' viewpoint, we should use transitive verbs' possible expression. Transitive verbs' possible expression shows that someone had a direct hand in the action (direct object). Nevertheless when we want to express the change or result of something from objects' viewpoint, we should use intransitive verbs' possible expression. The possible expression of intransitive verbs describes the objective status of the subject's wish.

For example:

doa ga akimasen (Door couldn't be opened.).

ryoute ga fusagatteiru node, akeraremasen(My hands stuffed with something, so I cannot open the door.).

doushitemo kuruma ga tomaranai (No matter how I do the car could not to stop. ).

watashi ha tomegata o shiranai kara tomerarenai (The car can't stop, because I don't know how to let the car stopped.).

In a foreign teacher's conversation class, when we want to open the windowsbut failed, we always say "doa ga akeraremasen"; however, the Japanese teachers said it was a non-authentic Japanese expression. "doa ga akimasen" is the Japanese expression. Then, when should we use the possible expression of intransitive verbs? The answer is that when our hands are occupied and cannot be applied into the action of opening the window. For example, "ryoute ga fusagatte irunode". When we lost control of the car we are driving, the possible state of transitive verbs "toustuitemo tomerarenai" cannot be applied here, but the expression containing the intransitive verb "doustuitemo tomaranai" sounds more natural. If it were the case that the car cannot be stopped because of the lack of experience of the driver, or the limit of the external condition, the possible expression of transitive verbs should be used. Therefore, this paper summarizethe intransitive-transitive verb pairs' possible expression in Fig.1. 
Transitive verb $\{$ Emphasis on persons' ability itself

Persons' Viewpoint $\{$ possible expression of beyond the conditions of subject itself

Intransitive verb $\{$ possible expression of the nature or state of an object itself

Object' Viewpoint $\{$ possible expression of the action, process, and outcome of an object

Fig.1 Intransitive-Transitive Verb Pairs' Possible Expression

\section{The Differences of Transitive-Intransitive Verb Non-Pair Possible Expression}

Hideo Teramura said: "As long as one verb have its possible expression which must be filled with the will". Transitive verbs generally have will so the verbs could have theirs possible expression. However, intransitive verbs are divided into intransitive verbs with will and intransitive verbs with no-will in accordance with the will such as: intransitive verbs with will "iku", "kuru", "au", "asobu" etc; intransitive verbs with no-will "aru", "iru", "akiru" etc.

raisyu no gestuyoubi,hoteru no robii de hayashi san to aemasu (I can meet Mr.lin in the hotel lobby next Monday.).

kodomotachi mo sicyuushin no kouen deno undousisestu ga asobaremasu (The kids can also play the sports facilities in the park.).

and (2) sentences express the possible expression of intransitive verbs with will. Whether not the intransitive verbs in pair which haven't will or the intransitive verbs which haven't transitive pairhave possible meanings by themselves. The intransitive verbs that haven't will express the result or change of subject, and the result or change beyond one's wish or will. But transitive verbs' possible expression is that the subjects have strong will or wish to achieve something. Intransitive verbs' possible expression as illustrated in table 1.

Table 1 Intransitive verbs' possible expression

\begin{tabular}{|c|c|c|c|}
\hline $\begin{array}{l}\text { The examples } \\
\text { of intransitive }\end{array}$ & subject & $\begin{array}{l}\text { Possible state "(ra) } \\
\text { Reru"."kotogadekiru" }\end{array}$ & Example sentences \\
\hline astumaru, naru & $\begin{array}{l}\text { person or thing } \\
\text { as the subject }\end{array}$ & The & $\begin{array}{l}\text { Hito ga takusan atumarimashita. } \\
\text { Hito ga astumareru basyo o } \\
\text { stukurimasu. }\end{array}$ \\
\hline tastukaru, ukaru & $\begin{array}{l}\text { Sentientsomething } \\
\text { as the subject }\end{array}$ & $x$ & Oboreta hito ga tastukarimasita. \\
\hline kiku, hairu & Something as the subject & $x$ & Mado ga aiteimasu. \\
\hline mieru & $\begin{array}{l}\text { Sentient something or inanimate } \\
\text { object as the subject }\end{array}$ & $x$ & Koko kara Fujisan ga mieru. \\
\hline
\end{tabular}

\section{Possible Expression of Transitive-Intransitive Verbs Sharing the Same Form}

For the transitive-intransitive same form verbs, they can be divided into two types to be treated. As the verb with will we should use transitive verbs' possible state emphasizing their ability or external conditions from "persons' viewpoint"; as the verb with non-will we should use intransitive verbs sentence emphasizing their nature and status or the course of action and results. As illustrated in table 2.

Table 2 Possible expression of transitive-intransitive verbs

\begin{tabular}{l|l|l}
\hline Intransitive verbs & Transitive verbs & Possible state \\
\hline Kaze ga fuku/ & Fue o fuku/ & Fue ga fukareru. \\
\hline Mon ga aku/The door was open & Mon o aku/open the door. & mon ga akareru. \\
\hline
\end{tabular}

\section{Conclusions}

This paper reports one of the important reasons for misusing transitive-intransitive verbs is thinking differences between Chinese and Japanese culture. Japanese devote much attention to the harmony between human and natures embody "Static character" in their language, thus deposing Japanese people 
tending to use intransitive verbs. The Japanese are inclined to observe the development trend of things from "Objects' Viewpoint". Japanesecontact with people in the way of heart to heart. Therefore, when the action of subject is emphasized, the transitive verbs assuming responsibility will generally be used. This reveals that when we are learning transitive-intransitive verbs, not only the differences between transitive verbs and intransitive verbs in grammar should be paid much attention, but theunderstanding of Japanese culture should also be emphasized. This paper analyses the possible expression of intransitive verb and transitive verb in Japanese from Persons' Viewpoint and Objects' Viewpoint andit is hoped thatthe paper can help and guide the Japanese learners. In addition, Japanese learnersare often confused about the transitive-intransitive verbs' passive state, which will be discussed in the future studies.

\section{Acknowledgements}

This work was supported in part by teaching reform project of Ministry of Education of PRC (JG2012010372).

\section{References}

[1] Li Shuzhi, Practical Japanese Grammar [M], Heilongjiang Education Press, 2004, pp. 45 46.

[2] YAMAOKA Masaki and Zhang Wei, Japanese verbs and related research, Beijing,foreign language and research press, 2011, 116 124.

[3] Zhang Linsheng, Analysis of Common Misuses, Beijing, Higher education press, 2011, pp. 81 91.

[4] Zhouping and Chen Xiaofen, New Japanese [M], Shanghai, Shanghai foreign language education press, 2011, pp.181 182.

[5] Li Wei and Tian Mi. 2012, A Study on Application of Sino-Japanese Culture in Teaching of Japanese Vi. and Vt. Research on Japan,2012, pp. 60 64.

[6] IORI Osao, New Japanese entry [M], Tokyo, Suriieenettowaaku press, 2007, pp. 128 139.

[7] HiNo Sukenari, Contemporary basic Japanese [M], Tokyo, Histuji press, 2009, pp. 142 152.

[8] Morita Yoshiyuki, Japanese Intransitive verbs and Transitive verbs [M]. Department of Japanese grammar 6, Meiji Shoin 1989. 